\title{
Design, Simulation and Experimental Validation of Wideband DGS Circularly Polarized Micro Strip Patch Antenna For C-Band Satellite Communication Applications
}

\author{
Karedla Chitambara Rao
}

\begin{abstract}
Satellites are very prominent for current and future communication applications like broadcasting, 5G and Military Communications. Most of the Satellites are used for radio communication. For communicating purpose, the satellite antenna must have unique characteristics such as circular polarization, broad beam width and good axial ratio. In order to have such type of unique characteristics, the micro strip patch antenna is the suitable antenna for Satellite applications because of its advantages. In this paper, a Wide band DGS circularly polarized micro strip patch antenna has been proposed for C-Band Satellite Communication Applications. Two defects or slots are introduced in the ground plane and those are orthogonally overlapped to get the circular polarization characteristics. In addition to this, these two slots enhance the bandwidth of the patch antenna by tuned to different frequencies. Moreover, the patch with defective ground structure is simulated and fabricated. Also measurements are carried out and obtained results are compared with the simulated results. It is noted that all the simulated and measured radiation patterns of the antenna have been carried out for all the frequencies and data has been compiled. However, some of the simulated and measured radiation patterns are included in this paper due to space constraint.
\end{abstract}

Keywords:Micro strip patch antenna, Defective Ground structure and C-Band Satellite Communication.

\section{INTRODUCTION}

The drawbacks of the ordinary micro strip patch antenna are low gain and low bandwidth. The low gain and low bandwidth can be improved by using so many techniques. Out of them, defective ground structure is the familiar technique to improve the gain and bandwidth. Defective ground structure technique is nothing but a creating a defect or slot on the ground plane. This defect will acts as a parallel tuned circuit which resonate at a required frequency by modifying the slot based on the proper measurements.

Two slots are required in overlap manner to get a circular polarization which is essential for satellite communication applications. Based on the DGS technique, the antenna can be operated at a multiple frequencies which lead to the enhancement of bandwidth of the antenna. The frequency for

Revised Manuscript Received on August 20, 2019.

Karedla Chitambara Ra**, Associate Professor in Electronics and Communication Engineering, Aditya Institute of Technology and Management (AITAM), Tekkali, Srikakulam, Andhra Pradesh, India. the $\mathrm{C}$-Band is allocated in the electromagnetic spectrum from $4 \mathrm{GHz}$ to $8 \mathrm{GHz}$. C-Band is mostly used for the communication applications like Wi-Fi, Wi-Max and $4 \mathrm{G}$ Communications. C-Band frequencies are used for both downlink and up link purpose. The frequency range of downlink is from $3.7 \mathrm{GHz}$ to $4.2 \mathrm{GHz}$ and $5.925 \mathrm{GHz}$ to $6.425 \mathrm{GHz}$ for uplink. Nakano, et al. [1-7] had explained about circular polarization and how it obtained from the patch antenna. Circular polarization may also be achieved by feeding the two orthogonal lines in $\mathrm{TM}_{01}$ and $\mathrm{TM}_{10}$ modes. Horizontal polarized wave can be obtained in $\mathrm{TM}_{01}$ mode and vertical polarized wave in $\mathrm{TM}_{10}$ mode respectively. Moreover, these two waves can be achieved simultaneously from a square patch antenna. A. Iwasaki, et al. [8] had designed a micro strip patch antenna with circular polarization characteristics. The circular polarization characteristics were obtained by using the crossed slots and their lengths are different. The designed antenna has been resonated at a frequency of $1575.42 \mathrm{MHz}$. The fundamental mode ( $T M_{11}$ mode) of circular patch antenna was obtained by

selecting the proper lengths of the slots. Moreover, the circular polarization was achieved by using equal amplitudes and $90^{\circ}$ phase difference. The patch and feed lines are fabricated on $1.6 \mathrm{~mm}$ substrate and its dielectric constant is 2.6. Right hand circular radiation was achieved by making the

length of slot 1 greater than the length of slot 2.Similarly, left hand circular polarization was achieved by making the length of slot 1 smaller than the length of slot $2.36 \%$ size reduction was achieved when compared to ordinary patch. Better measurement values are achieved like VSWR is 2:1 and axial ratio less than 3dB. Z.N.Nasimuddin, et al. [9] had designed a circular polarized micro strip patch antenna for the frequency range of $2.397 \mathrm{GHz}$ to $2.512 \mathrm{GHz}$. Circular polarization may also achieved by using the asymmetric slots with different length. The designed antenna has been fabricated on an FR4 substrate with thickness of $1.6 \mathrm{~mm}$. When compared to ordinary patch, $12 \%$ size reduction was obtained .Moreover, better measurement values are also achieved such as $10-\mathrm{dB}$ return loss and $3-\mathrm{dB}$ axial ratio bandwidth.

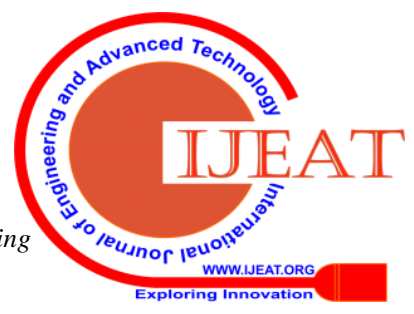


Design, Simulation and Experimental Validation of Wideband DGS Circularly Polarized Micro strip patch antenna for C-Band Satellite Communication Applications

\section{DESIGN EQUATIONS}

For an efficient antenna, the width (W) is given by the formulae

$$
W=\frac{c}{2 f_{r}} \sqrt{\frac{2}{\epsilon_{r}+1}}
$$

Where $\mathrm{c}$ is the free space velocity

$$
\epsilon_{Y}=\text { dielectric constant }
$$

The effective dielectric constant ( $\varepsilon_{\text {yeff }}$ ) of the micro strip patch antenna is

$\epsilon_{\text {reff }}=\frac{\epsilon_{r}+1}{2}+\frac{\epsilon_{r}-1}{2}\left(1+12 \frac{\hat{h}}{w}\right)^{-\frac{1}{2}} \frac{w}{h}>1$

The extension length $(\Delta \mathrm{L})$ is given by the following formulae

$$
\Delta L=0.412 h \frac{\left(\epsilon_{y}+0.3\right)\left(\frac{w}{h}+0.264\right)}{\left(\varepsilon_{y}-0.258\right)\left(\frac{w}{h}+0.8\right)}
$$

Effective length $\left(\mathrm{L}_{\mathrm{eff}}\right)$ is calculated by using the formulae

$$
L_{\text {eff }}=\frac{c}{2 f_{\mathrm{r}} \sqrt{E_{\mathrm{raff}}}}
$$

The actual length of the patch is calculated by using the formulae.

$$
\mathrm{L}=\mathrm{L}_{\mathrm{eff}}-2 \Delta \mathrm{L} \text {. }
$$

\section{DESIGN SPECIFICATIONS}

The specifications in the Table I are considered for the C-Band patch antenna.

Table-I:Design Specifications Of C-Band Patch Antenna

\begin{tabular}{|c|c|c|}
\hline S.No & Design parameter & Specification \\
\hline 1 & Receiving frequency range & $3700 \mathrm{MHz}-4200 \mathrm{MHz}$ \\
\hline 2 & Transmitting frequency range & $5900 \mathrm{MHz}-6400 \mathrm{MHz}$ \\
\hline 3 & VSWR & $3: 1(\mathrm{Max})$ \\
\hline 4 & Gain & $\begin{array}{c}-3 \mathrm{dBi}(\mathrm{Min}) \text { to } \\
+3 \mathrm{dBi}(\mathrm{Max})\end{array}$ \\
\hline 5 & Polarization & $\mathrm{LHCP}$ \\
\hline 6 & Beam width & $\operatorname{Max}\left(90^{0}\right), \mathrm{Min}\left(17.03^{0}\right)$ \\
\hline 7 & Axial ratio & $\leq 5 \mathrm{~dB}$ \\
\hline 8 & Spatial coverage & Overtop hemisphere \\
\hline 9 & Connector & SMA \\
\hline 10 & Input impedance & $50 \Omega$ \\
\hline
\end{tabular}

\section{DESIGN PARAMETERS}

Design parameters of C-Band Micro strip patch antenna are calculated based on the design equations, which are presented in the section II.

Table-II:Design Parameters Of C-Band Micro Strip Patch Antenna With Defective Ground Structure

\begin{tabular}{|c|c|c|}
\hline S.No & Design parameter & $\begin{array}{c}\text { Calculated } \\
\text { value }\end{array}$ \\
\hline 1 & Resonant frequency & $5.05 \mathrm{GHz}$ \\
\hline 2 & $\begin{array}{l}\text { Ground plane (Copper) } \\
\text { thickness }\end{array}$ & $0.1 \mathrm{~mm}$ \\
\hline 3 & Ground plane length & $23.37 \mathrm{~mm}$ \\
\hline 4 & Ground plane width & $27.87 \mathrm{~mm}$ \\
\hline 5 & $\begin{array}{l}\text { Substrate (FR4 Lossy) } \\
\text { thickness }\end{array}$ & $1.6 \mathrm{~mm}$ \\
\hline 6 & Substrate dielectric constant & 4.3 \\
\hline 7 & Patch (Copper) thickness & $0.1 \mathrm{~mm}$ \\
\hline
\end{tabular}

\begin{tabular}{|c|c|c|}
\hline 8 & Patch length & $13.77 \mathrm{~mm}$ \\
\hline 9 & Patch width & $18.24 \mathrm{~mm}$ \\
\hline 10 & Large slot(Defect) length & $2.4 \mathrm{~mm}$ \\
\hline 11 & Large slot(Defect) width & $1 \mathrm{~mm}$ \\
\hline 12 & Small slot (Defect) length & $1.2 \mathrm{~mm}$ \\
\hline 13 & Small slot (Defect) length & $0.5 \mathrm{~mm}$ \\
& & \\
\hline
\end{tabular}

\section{SIMULATED MICRO STRIP PATCH ANTENNA WITH DEFECTIVE GROUND STRUCTURE}

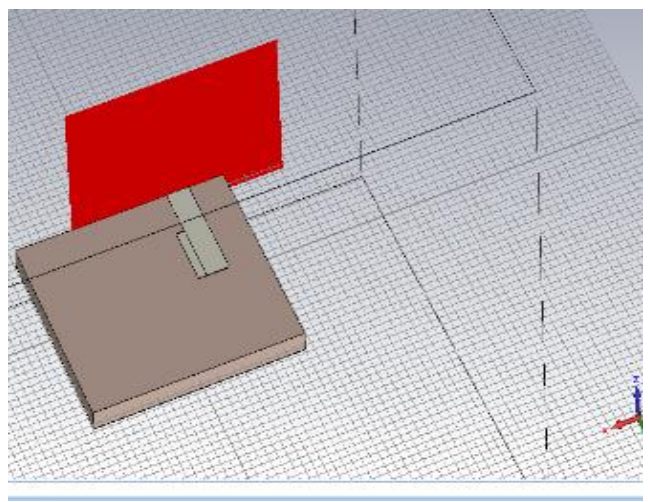

Fig.1.Simulated Micro strip patch antenna with Defective Ground Structure

In the Fig.1, the exciting points of the both the slots (defects) are orthogonal to each other for providing the circular polarization at the resonating frequencies. The co-axial type of feeding technique has been used for this antenna.

\section{SIMULATION RESULTS}

The C-Band Micro strip patch antenna is designed at a centre frequency of 5.05GHz.The designed antenna was simulated and analyzed for the various characteristics like VSWR, Gain, axial ratio, 3-dB beam width and Radiation patterns at the various receiving and transmitting frequencies. Gain and axial ratio of the antenna are taken at the different angles of $\theta$ $\left(-45^{0}, 0^{0} \& 45^{\circ}\right)$ by fixing the $\varphi$ at $0^{0}$ for analysis. Radiation patterns such as 3D and 2D radiation patterns are also taken at the various frequencies for analysing the radiation characteristics.

\section{A. Simulated VSWR}

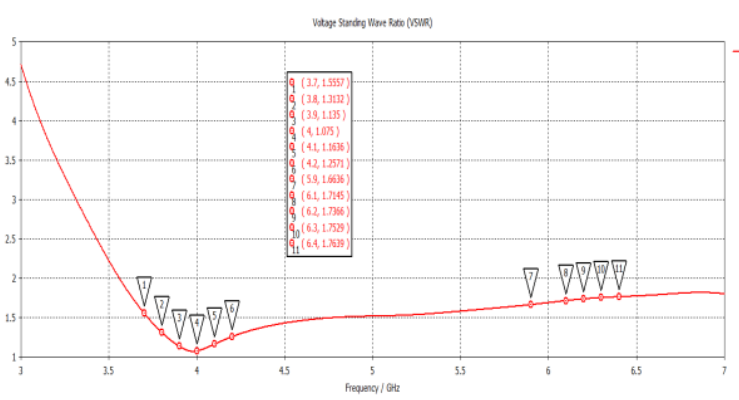

Fig.2.Simulated VSWR versus frequency

Published By: 
Table-III : Simulated VSWR At Various Receiving And Transmitting Frequencies

\begin{tabular}{|c|c|c|c|}
\hline $\begin{array}{c}\text { Frequency } \\
\text { (MHz) }\end{array}$ & VSWR & $\begin{array}{c}\text { Frequency } \\
\text { (MHz) }\end{array}$ & VSWR \\
\hline 3700 & 1.5557 & 5900 & 1.6636 \\
\hline 3800 & 1.3122 & 6000 & 1.6737 \\
\hline 3900 & 1.135 & 6100 & 1.7145 \\
\hline 4000 & 1.075 & 6200 & 1.7366 \\
\hline 4100 & 1.1636 & 6300 & 1.7529 \\
\hline 4200 & 1.2571 & 6400 & 1.7639 \\
\hline
\end{tabular}

The Fig. 2 shows that VSWR versus frequency. In the Table 3 , the simulated VSWR values are obtained from the Fig.2. From the Table 3, it is noted that the low VSWR values at the receiving and transmitting frequencies are 1.075 at $4000 \mathrm{MHz}$ and 1.6636 at $5900 \mathrm{MHz}$ respectively. These values are good and suitable for C-Band Satellite Communication applications.

\section{B. Simulated Gain}

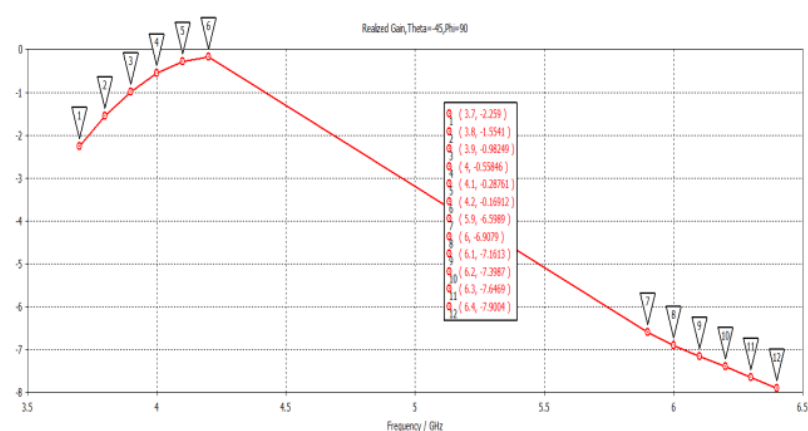

Fig.3.Simulated Gain versus frequency at $\theta=-45^{0}$ ver Gin in fitumen

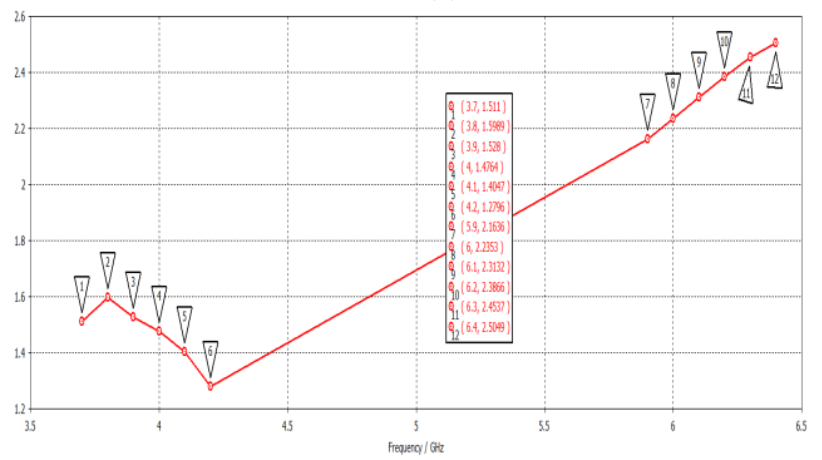

Fig.4.Simulated Gain versus frequency at $\theta=0^{0}$

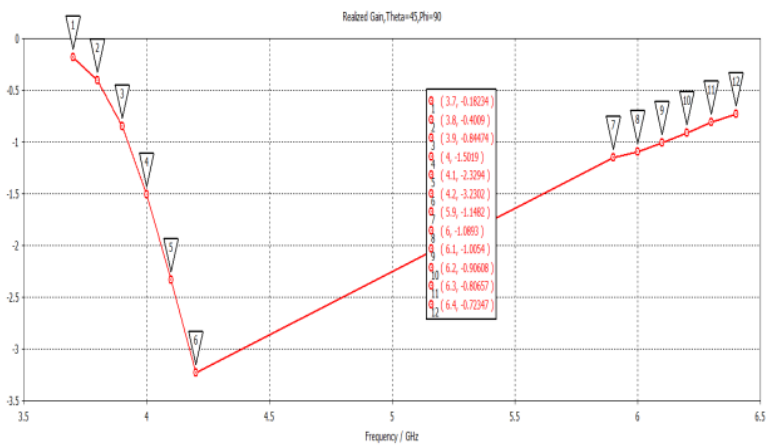

Fig.5.Simulated Gain versus frequency at $\theta=45^{\circ}$
Table-IV: Simulated Gain At Different Angles Of $\Theta$ For Various Receiving And Transmitting Frequencies.

\begin{tabular}{|c|c|c|c|}
\hline \multirow{2}{*}{$\begin{array}{c}\text { Frequency } \\
(\mathbf{M H z})\end{array}$} & \multicolumn{3}{|c|}{ Simulated Gain(dBi) } \\
\cline { 2 - 4 } & $\boldsymbol{\theta = - \mathbf { 4 5 } ^ { \mathbf { 0 } }}$ & $\mathbf{\theta = 0}^{\mathbf{0}}$ & $\boldsymbol{\theta = \mathbf { 4 5 } ^ { \mathbf { 0 } }}$ \\
\hline 3700 & -2.259 & 1.511 & -0.1853 \\
\hline 3800 & -1.5541 & 1.5989 & -0.4009 \\
\hline 3900 & -0.98249 & 1.528 & -0.8447 \\
\hline 4000 & -0.55846 & 1.4764 & -1.5019 \\
\hline 4100 & -0.28761 & 1.4047 & -2.3294 \\
\hline 4200 & -0.16912 & 1.2796 & -3.2302 \\
\hline 5900 & -6.5989 & 2.1636 & -1.1482 \\
\hline 6000 & -6.9079 & 2.2353 & -1.0893 \\
\hline 6100 & -7.1613 & 2.3132 & -1.0054 \\
\hline 6200 & -7.3987 & 2.3866 & -0.9060 \\
\hline 6300 & -7.6469 & 2.4537 & -0.8065 \\
\hline 6400 & -7.9004 & 2.5039 & -0.7234 \\
\hline
\end{tabular}

The figures 3 to 5 show that Gain versus frequency at the different angles of $\theta\left(-45^{\circ}, 0^{0} \& 45^{\circ}\right)$. In the TABLE 4 , the simulated Gain is obtained at different angles of $\theta$ from the figures 3 to 5 . From the above Table 4 , it is noted that the highest gain values are obtained at $0^{0}$ when compared to the $-45^{\circ}$ and $+45^{\circ}$. It is also noted that, the higher Gain values at $0^{\circ}$ for receiving and transmitting frequencies are $1.5989 \mathrm{dBi}$ at $3800 \mathrm{MHz}$ and $2.5039 \mathrm{dBi}$ at $6400 \mathrm{MHz}$ respectively. Similarly at $-45^{\circ}$ and $+45^{\circ}$, the higher Gain values are $-0.28761 \mathrm{dBi}$ at $4100 \mathrm{MHz},-6.5989 \mathrm{dBi}$ at $5900 \mathrm{MHz}$, $0.1853 \mathrm{dBi}$ at $3700 \mathrm{MHz}$ and $-0.7234 \mathrm{dBi}$ at $6400 \mathrm{MHz}$ respectively. These higher Gain values are good and suitable for C-Band Satellite Communication applications.

\section{Simulated Axial Ratio}

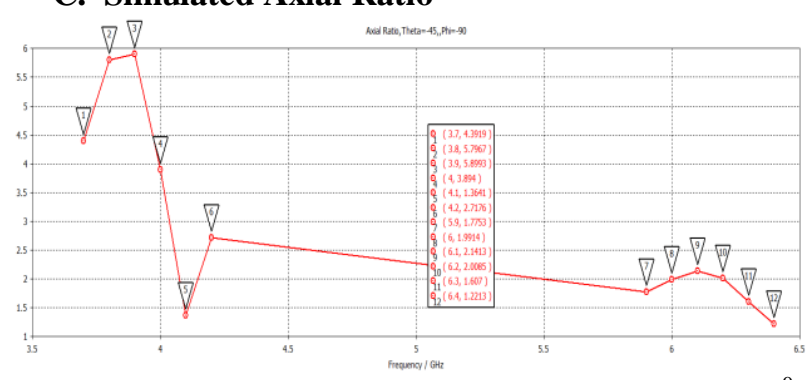

Fig.6.Simulated axial ratio versus frequency at $\theta=-45^{0}$

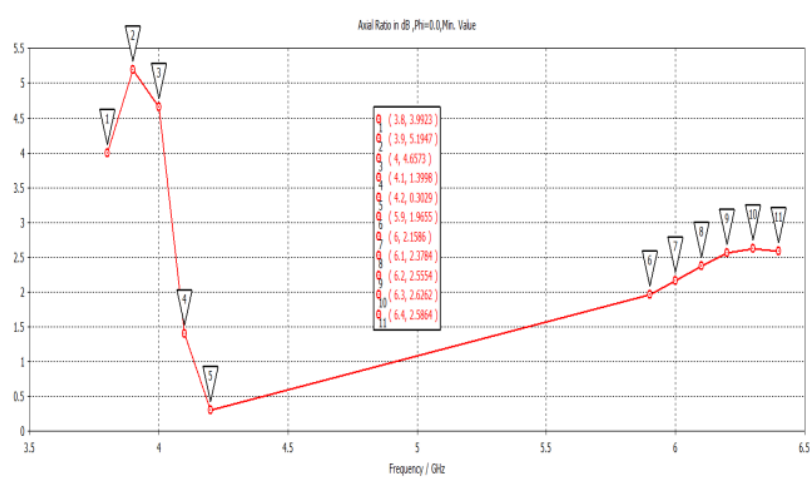

Fig.7.Simulated axial ratio versus frequency at $\theta=0^{0}$

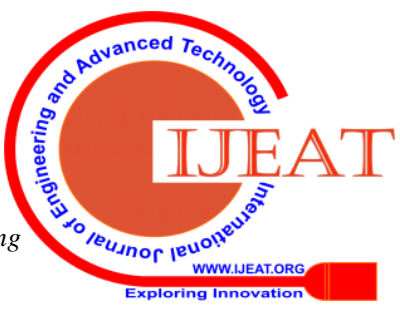


Design, Simulation and Experimental Validation of Wideband DGS Circularly Polarized Micro strip patch antenna for C-Band Satellite Communication Applications

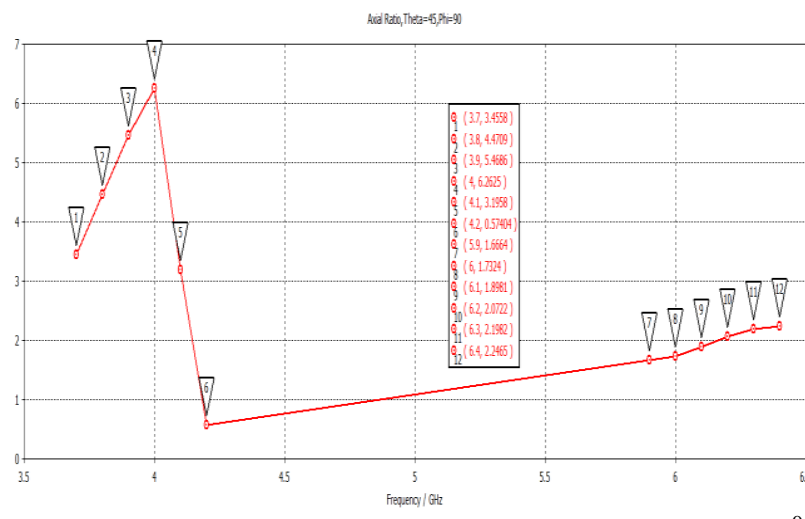

Fig.8.Simulated axial ratio versus frequency at $\theta=45^{\circ}$

Table-V:Simulated Axial Ratio At Different Angles Of $\theta$ For Various Receiving And Transmitting Frequencies

\begin{tabular}{|c|c|c|c|}
\hline \multirow{2}{*}{$\begin{array}{c}\text { Frequency } \\
\text { (MHz) }\end{array}$} & \multicolumn{3}{|c|}{ Simulated axial ratio $(\mathrm{dB})$} \\
\hline & $\theta=-45^{0}$ & $\theta=0^{0}$ & $\theta=45^{0}$ \\
\hline 3700 & 4.3919 & 3.9521 & 3.4558 \\
\hline 3800 & 5.7967 & 3.9923 & 4.4709 \\
\hline 3900 & 5.8993 & 5.1947 & 5.4686 \\
\hline 4000 & 3.894 & 4.6573 & 6.2625 \\
\hline 4100 & 1.3641 & 1.3998 & 3.1958 \\
\hline 4200 & 2.7176 & 0.3029 & 0.5740 \\
\hline 5900 & 1.7753 & 1.9655 & 1.6664 \\
\hline 6000 & 1.9914 & 2.1586 & 1.7324 \\
\hline 6100 & 2.1413 & 2.3784 & 1.8981 \\
\hline 6200 & 2.0085 & 2.5554 & 2.0722 \\
\hline 6300 & 1.607 & 2.6262 & 2.1982 \\
\hline 6400 & 1.2213 & 2.5864 & 2.2465 \\
\hline
\end{tabular}

The figures 6 to 8 show that axial ratio versus frequency at the different angles of $\theta\left(-45^{\circ}, 0^{\circ} \& 45^{\circ}\right)$. In the TABLE 5, the simulated axial ratio is obtained at different angles from the figures 6 to 8. From the above TABLE 5, it is noted that lower axial ratio values at $0^{0}$ for the receiving and transmitting frequencies are $0.3029 \mathrm{~dB}$ at $4200 \mathrm{MHz}$ and $1.9655 \mathrm{~dB}$ at $5900 \mathrm{MHz}$ respectively. Similarly at $-45^{\circ}$ and $+45^{\circ}$, the lower axial ratio values are $1.3641 \mathrm{~dB}$ at $4100 \mathrm{MHz}, 1.2213 \mathrm{~dB}$ at $6400 \mathrm{MHz}, 0.574 \mathrm{~dB}$ at $4200 \mathrm{MHz}$ and $1.6664 \mathrm{~dB}$ at $5900 \mathrm{MHz}$ respectively. These lower axial ratio values are good according to the given design specifications and suitable for C-Band Satellite Communication applications.

D. Simulated Radiation Patterns at Receiving and Transmitting Frequencies

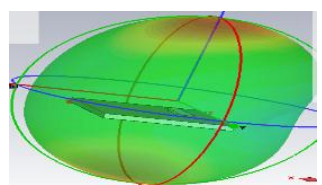

(a) 3-D Pattern

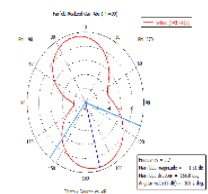

(b) 2-D Pattern
Fig.9.Simulated radiation pattern at $3700 \mathrm{MHz}$

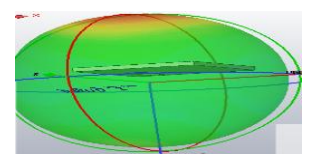

(a) 3-D Pattern

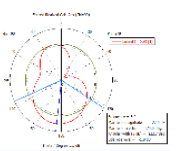

(b) 2-D Pattern
Fig.10.Simulated radiation pattern at $5900 \mathrm{MHz}$
Table-VI:Simulated 3-Db Beam Width At Various Receiving And Transmitting Frequencies

\begin{tabular}{|c|c|c|c|}
\hline $\begin{array}{c}\text { Frequency(M } \\
\text { Hz) }\end{array}$ & $\begin{array}{c}\text { 3-dB beamwidth } \\
\text { (deg) }\end{array}$ & $\begin{array}{c}\text { Frequency( } \\
\text { MHz) }\end{array}$ & $\begin{array}{c}\text { 3-dB } \\
\text { beamwidth } \\
\text { (deg) }\end{array}$ \\
\hline 3700 & 108.2 & 5900 & 122.7 \\
\hline 3800 & 111.9 & 6000 & 119.3 \\
\hline 3900 & 120.2 & 6100 & 115.8 \\
\hline 4000 & 256.3 & 6200 & 112.7 \\
\hline 4100 & 249.6 & 6300 & 110.1 \\
\hline 4200 & 243.6 & 6400 & 108.2 \\
\hline
\end{tabular}

The figures 9 to 10 show that simulated 3D and 2D radiation patterns at various receiving and transmitting frequencies. In the Table 6 , the simulated $3-\mathrm{dB}$ beam width values are obtained from the $2 \mathrm{D}$ radiation patterns. From the above Table 6 , it is noted that the higher $3-\mathrm{dB}$ beam width value for the both receiving and transmitting frequencies are $256.3^{\circ}$ at $4000 \mathrm{MHz}$ and $122.7^{0}$ at $5900 \mathrm{MHz}$ respectively. The higher 3-dB beam width values are best and suitable for C-Band Satellite Communication applications.

\section{FABRICATION AND MEASUREMENT RESULTS}

The Fig. 11 shows that fabricated C-Band patch antenna. This antenna is measured for various characteristics such as VSWR, Gain, axial ratio, 3-dB beam width and Radiation patterns at the various receiving and transmitting frequencies
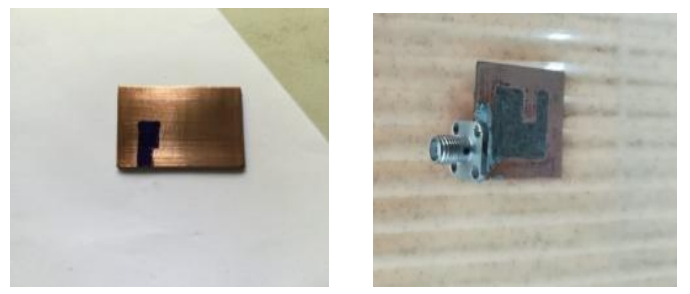

Fig.11.Fabricated C-Band Micro strip patch antenna

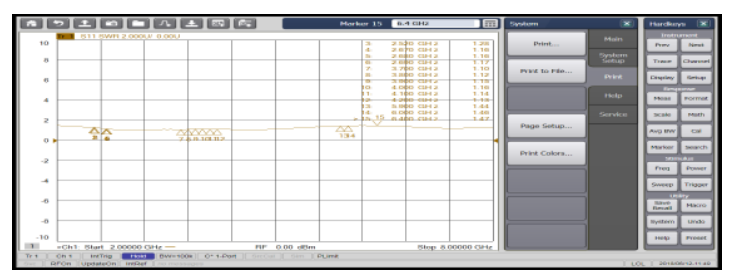

Fig.12.Measured VSWR versus frequency

Table-VII: Measured VSWR At Various Receiving And Transmitting Frequencies

\begin{tabular}{|c|c|c|c|}
\hline $\begin{array}{c}\text { Frequency } \\
\text { (MHz) }\end{array}$ & VSWR & $\begin{array}{c}\text { Frequency } \\
\text { (MHz) }\end{array}$ & VSWR \\
\hline 3700 & 1.1 & 5900 & 1.44 \\
\hline 3800 & 1.12 & 6000 & 1.46 \\
\hline
\end{tabular}

Published By:

Blue Eyes Intelligence Engineering 


\begin{tabular}{|l|l|l|l|}
\hline 3900 & 1.15 & 6100 & 1.47 \\
\hline 4000 & 1.16 & 6200 & 1.47 \\
\hline 4100 & 1.14 & 6300 & 1.47 \\
\hline 4200 & 1.13 & 6400 & 1.47 \\
\hline
\end{tabular}

The Fig.12 shows that VSWR versus frequency. In the TABLE 7, the measured VSWR values are obtained from the Fig.12. From the TABLE 7, it is noted that the lower VSWR values at the receiving and transmitting frequencies are 1.1 at $3700 \mathrm{MHz}$ and 1.44 at $5900 \mathrm{MHz}$ respectively. The lower VSWR values are good and suitable for C-Band Satellite Communication applications.

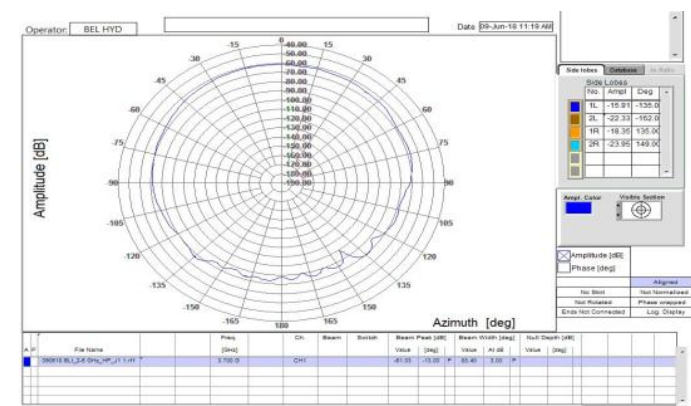

Fig.13. Measured radiation pattern in Horizontal Polarization at $3700 \mathrm{MHz}$

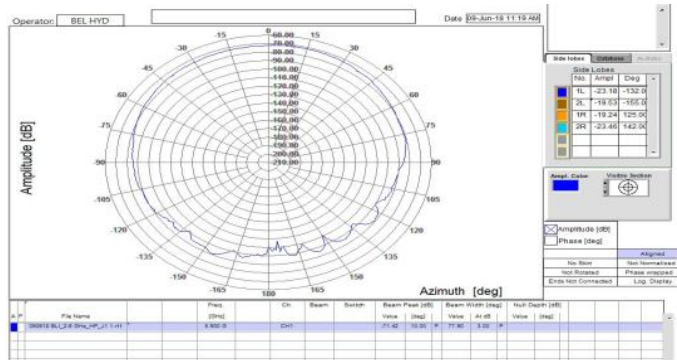

Fig.14. Measured radiation pattern in Horizontal Polarization at $5900 \mathrm{MHz}$

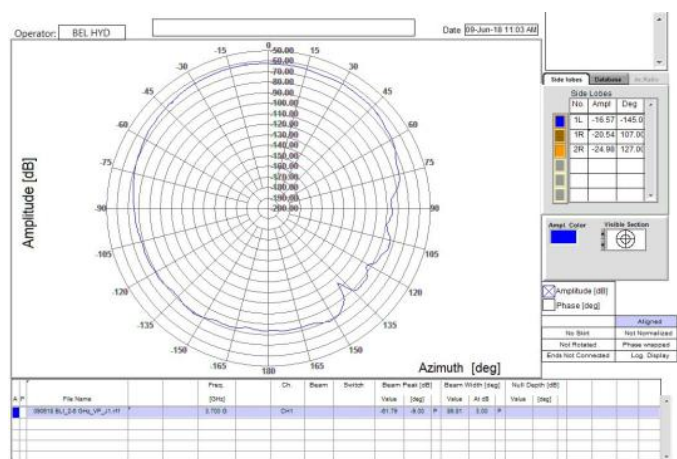

Fig.15.Measured radiation pattern in Vertical Polarization at $3700 \mathrm{MHz}$

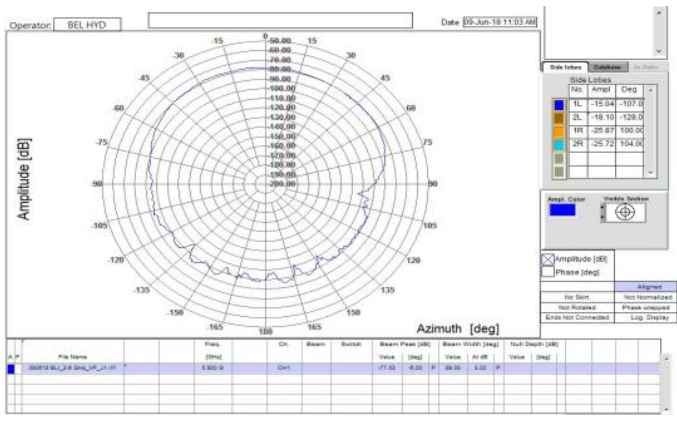

Fig.16. Measured radiation pattern in Vertical Polarization at $5900 \mathrm{MHz}$
The measured 3-dB beam width values are taken from the measured radiation patterns in Horizontal and Vertical Polarizations, which are presented in the sections (b) and (c) of VII

Table-VIII: Measured 3-Db Beam Width Of Antenna Under Test In Horizontal And Vertical Polarizations At Various Receiving And Transmitting Frequencies

\begin{tabular}{|c|c|c|}
\hline \multirow[b]{2}{*}{$\begin{array}{c}\text { Frequency } \\
\text { (MHz) }\end{array}$} & \multicolumn{2}{|c|}{ Measured 3-dB beam width (deg) } \\
\hline & $\begin{array}{c}\text { 3-dB beam width of } \\
\text { AUT in Horizontal } \\
\text { Polarization }\end{array}$ & $\begin{array}{c}\text { 3-dB beam width of } \\
\text { AUT in Vertical } \\
\text { Polarization }\end{array}$ \\
\hline 3700 & 83.4 & 89.81 \\
\hline 3800 & 75.5 & 61.92 \\
\hline 3900 & 93.59 & 74.93 \\
\hline 4000 & 93.77 & 81.37 \\
\hline 4100 & 80.37 & 81.93 \\
\hline 4200 & 99.93 & 58.47 \\
\hline 5900 & 77.9 & 89 \\
\hline 6000 & 58.06 & 77.61 \\
\hline 6100 & 62.36 & 62.84 \\
\hline 6200 & 74.85 & 30.92 \\
\hline 6300 & 76.41 & 45.37 \\
\hline 6400 & 73.28 & 56.71 \\
\hline
\end{tabular}

From the TABLE 8, it has been observed that the higher $3-\mathrm{dB}$ beam width values in Horizontal and Vertical polarizations are $99.93^{\circ}$ at $4200 \mathrm{MHz}, 77.9^{\circ}$ at $5900 \mathrm{MHz}$, $89.81^{\circ}$ at $3700 \mathrm{MHz}$ and $89^{\circ}$ at $5900 \mathrm{MHz}$ respectively. The higher 3-dB beam widths values are good and suitable for C-Band Satellite Communication applications.

\section{A. Measured Beam Peak and Standard Antenna Gain for Various Receiving and Transmitting Frequencies.}

AUT Beam peak values are obtained at different angles from the measured radiation patterns in Horizontal and Vertical polarizations, which are presented in the sections (b) and (c) of VII

\section{B. Measured Gain in Vertical Polarization}

Measurement of Gain is carried out in Vertical Polarization. Here AUT gain is calculated based on the AUT beam peak, Standard antenna beam peak, Standard antenna gain, Polarization losses and cable losses. In the TABLE 10, AUT Gain is calculated at different angles for each frequency based on the following equation.

AUT Gain = AUT Beam peak- Standard antenna beam peak + Standard antenna Gain $+3 \mathrm{~dB}$ polarization loss $+2 \mathrm{~dB}$ cable losses

In the equation (6), AUT beam peak, Standard antenna beam peak and Standard antenna Gain values are considered from the TABLE 9. From the TABLE 10, it is observed that the highest gain values are obtained at $0^{\circ}$ when compared to the $-45^{\circ}$ and $+45^{\circ}$. In Vertical Polarization, the higher Gain values for the receiving and transmitting frequencies at $0^{\circ}$ are $10.58 \mathrm{dBi}$ at $3700 \mathrm{MHz}$ and $8.58 \mathrm{dBi}$ at $6200 \mathrm{MHz}$ respectively. Similarly at $-45^{\circ}$ and $+45^{\circ}$, the highest Gain values are $7.143 \mathrm{dBi}$ at $3700 \mathrm{MHz}, \quad 6.649 \mathrm{dBi}$ $6100 \mathrm{MHz}, \quad 8.13 \mathrm{dBi}$

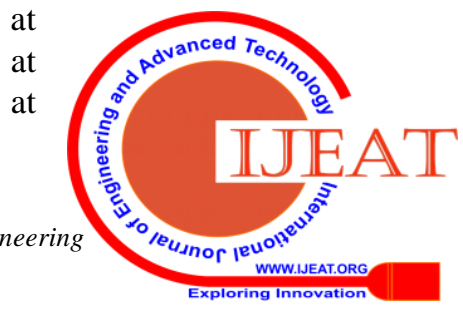


Design, Simulation and Experimental Validation of Wideband DGS Circularly Polarized Micro strip patch antenna for C-Band Satellite Communication Applications

$3700 \mathrm{MHz}$ and $7.773 \mathrm{dBi}$ at $6100 \mathrm{MHz}$ respectively. The obtained higher Gain values are good and suitable for C-Band Satellite Communication applications.

Table-IX: Measured AUT Beam Peak In Vertical Polarizations At Different Angles Of $\theta$, Standard Antenna Beam Peak And Standard Antenna Gain For Various Receiving And Transmitting Frequencies

\begin{tabular}{|c|c|c|c|c|c|}
\hline \multirow{2}{*}{$\begin{array}{l}\text { Frequency } \\
(\mathrm{MHz})\end{array}$} & \multicolumn{3}{|c|}{$\begin{array}{c}\text { AUT Beam peak } \\
\text { values }(\mathrm{dBm}) \text { in Vertical } \\
\text { Polarization }\end{array}$} & \multirow{2}{*}{$\begin{array}{l}\text { Standard } \\
\text { antenna } \\
\text { beam } \\
\text { peak }(\mathbf{d B m})\end{array}$} & \multirow{2}{*}{$\begin{array}{l}\text { Standard } \\
\text { antenna } \\
\text { Gain } \\
\text { (dBi) }\end{array}$} \\
\hline & $\begin{array}{c}\theta= \\
-45^{0}\end{array}$ & $\theta=0^{0}$ & $\theta=45^{0}$ & & \\
\hline 3700 & -65.22 & -61.79 & -64.239 & -48.17 & 19.2 \\
\hline 3800 & -70.97 & -64.36 & -66.017 & -46.62 & 19.3 \\
\hline 3900 & -72.70 & -71.79 & -75.386 & -48.46 & 19.4 \\
\hline 4000 & -69.76 & -65.56 & -68.704 & -48.7 & 19.5 \\
\hline 4100 & -68.69 & -63.46 & -65.986 & -49.15 & 17.4 \\
\hline 4200 & -69.98 & -67.04 & -71.841 & -51.19 & 17.6 \\
\hline 5900 & -79.69 & -77.52 & -80.296 & -52.63 & 21.72 \\
\hline 6000 & -84.65 & -79.19 & -83.86 & -53.9 & 21.8 \\
\hline 6100 & -85.26 & -79.11 & -84.137 & -65.01 & 21.9 \\
\hline 6200 & -88.32 & -85.43 & -91.793 & -67.06 & 21.95 \\
\hline 6300 & -94.00 & -84.54 & -91.934 & -64.1 & 22 \\
\hline 6400 & -96.02 & -87.46 & -92.247 & -62.96 & 22.1 \\
\hline
\end{tabular}

Table-X:Measured AUT Gain At Different Angles Of $\theta$ In Vertical Polarization For Various Receiving And Transmitting Frequencies

\begin{tabular}{|c|c|c|c|}
\hline \multirow{2}{*}{$\begin{array}{c}\text { Frequency } \\
(\mathbf{M H z})\end{array}$} & \multicolumn{3}{|c|}{ AUT Gain $(\mathbf{d B i})$ in Vertical Polarization } \\
\cline { 2 - 4 } & ${\boldsymbol{\theta}=\mathbf{- 4 5}^{\mathbf{0}}}^{\mathbf{0}}$ & $\boldsymbol{\theta = 0}^{\mathbf{0}}$ & $\mathbf{\theta = 4 5}^{\mathbf{0}}$ \\
\hline 3700 & 7.143 & $\not 0.58$ & 8.131 \\
\hline 3800 & -0.058 & 6.56 & 4.903 \\
\hline 3900 & 0.159 & 1.07 & -2.526 \\
\hline 4000 & 3.435 & 7.64 & 4.496 \\
\hline 4100 & 2.86 & 8.09 & 5.564 \\
\hline 4200 & 3.801 & 6.75 & 1.949 \\
\hline 5900 & -0.344 & 1.83 & -0.946 \\
\hline 6000 & -3.957 & 1.51 & -3.16 \\
\hline 6100 & 6.649 & 12.8 & 7.773 \\
\hline 6200 & 5.686 & 8.58 & 2.217 \\
\hline 6300 & -2.908 & 6.56 & -0.834 \\
\hline 6400 & -5.966 & 2.6 & -2.187 \\
\hline
\end{tabular}

\section{Measured Axial Ratio}

Axial ratio is calculated based on the measured AUT beam peak values of radiation patterns in Horizontal and Vertical Polarizations, which are presented in the sections (b) and (c) of VII

Table-XI:Measured Axial Ratio At Different Angles Of $\Theta$ For Various Receiving And Transmitting Frequencies

\begin{tabular}{|c|c|c|c|}
\hline \multirow{2}{*}{$\begin{array}{c}\text { Frequency } \\
(\mathbf{M H z})\end{array}$} & \multicolumn{3}{|c|}{ Measured axial ratio(dB) } \\
\cline { 2 - 4 } & $\boldsymbol{\theta = - 4 5}^{\mathbf{0}}$ & $\boldsymbol{\theta = 0}^{\mathbf{0}}$ & $\boldsymbol{\theta}=\mathbf{4 5}^{\mathbf{0}}$ \\
\hline 3700 & 3.227 & 0.76 & 1.739 \\
\hline 3800 & 1.478 & 0.24 & 3.983 \\
\hline 3900 & 3.201 & 5.41 & 5.386 \\
\hline 4000 & 1.735 & 3.95 & 2.296 \\
\hline 4100 & 0.31 & 0.92 & 3.014 \\
\hline 4200 & 0.489 & 0 & 1.841 \\
\hline 5900 & 4.694 & 6.1 & 5.296 \\
\hline 6000 & 0.657 & 1.62 & 1.86 \\
\hline 6100 & 9.739 & 9.27 & 10.863 \\
\hline 6200 & 1.676 & 3.59 & 2.207 \\
\hline 6300 & 10.008 & 5.27 & 6.934 \\
\hline 6400 & 14.026 & 9.45 & 7.247 \\
\hline
\end{tabular}

C-Band Satelle Communication Applications. The patch C-Band Satellite Communication Applications. The patch with defective ground structure is simulated and fabricated. Also measurements are carried out and obtained results are presented. The enhancement of bandwidth of patch antenna is achieved by using defective ground structure. In addition to this, all the simulated and measured values are obtained by using the DGS technique for the C-Band Satellite Communication applications. Moreover, the experimentally measured values are better when compared to simulated values.

From the measured results, the lower VSWR values are obtained at the receiving and transmitting frequencies as 1.1 at $3700 \mathrm{MHz}$ and 1.44 at $5900 \mathrm{MHz}$ respectively. The higher Gain values in Vertical Polarization are achieved at $0^{0}$ for the receiving and transmitting frequencies as $10.58 \mathrm{dBi}$ at $3700 \mathrm{MHz}$ and $8.58 \mathrm{dBi}$ at $6200 \mathrm{MHz}$ respectively. Similarly at $-45^{\circ}$ and $+45^{\circ}$, the higher Gain values are achieved as $7.143 \mathrm{dBi}$ at $3700 \mathrm{MHz}, 6.649 \mathrm{dBi}$ at $6100 \mathrm{MHz}, 8.13 \mathrm{dBi}$ at $3700 \mathrm{MHz}$ and $7.773 \mathrm{dBi}$ at $6100 \mathrm{MHz}$ respectively. The lower axial ratio values are obtained at $0^{\circ}$ for the receiving and transmitting frequencies as $0 \mathrm{~dB}$ at $4200 \mathrm{MHz}$ and $1.62 \mathrm{~dB}$ at $6000 \mathrm{MHz}$ respectively. Similarly at $-45^{\circ}$ and $+45^{\circ}$, the lower axial ratio values are obtained as $0.31 \mathrm{~dB}$ at $4100 \mathrm{MHz}$, $0.657 \mathrm{~dB}$ at $6000 \mathrm{MHz}, 1.739 \mathrm{~dB}$ at $3700 \mathrm{MHz}$ and $1.86 \mathrm{~dB}$ at $6000 \mathrm{MHz}$ respectively. The higher $3-\mathrm{dB}$ beam width values in Horizontal and Vertical polarizations are obtained for the receiving and transmitting frequencies as $99.93^{\circ}$ at $4200 \mathrm{MHz}, 77.9^{\circ}$ at $5900 \mathrm{MHz}, 89.81^{\circ}$ at $3700 \mathrm{MHz}$ and $89^{\circ}$ at $5900 \mathrm{MHz}$ respectively. It is concluded that all the measured values are best and suitable for C-Band Satellite Communication applications. Hence, patch antenna with DGS is accepted for C-Band Satellite Communication applications.

\section{REFERENCES}

1. H.Nakano, Helical and Spiral Antennas, "A Numerical Approach", Research Studies Press Ltd, 1987.

2. C.A. Balanis, Antenna Theory, Analysis and Design, Hoboken, NJ: John Wiley \& Sons, Inc., 2005.

3. W.L. Stutzman and G.A. Thiele, Antenna Theory and Design, 2nd edn, New York: John Wiley \& Sons, Inc., 1997. 
4. J.D. Kraus and R.J. Marhefka, Antennas for all Applications, New York: McGraw-Hill, 2002.

5. W.Imbraile, S. Gao and L. Boccia, "Space Antenna Handbook", Chichester: John Wiley \& Sons, Ltd,012.

6. D.M. Pozar and D. Schaubert, "Micro strip Antennas: The Analysis and Design of Micro strip Antennas and Arrays", New York: John Wiley \& Sons, Inc., 1995.

7. J.R. James and P.S. Hall, Handbook of Micro strip Antennas, IEEE Electromagnetic Waves Series, 1989.

8. H. Iwasaki, "A circularly polarized small-size micro strip antenna with a cross slot", Antennas and Propagation, IEEE Transactions,44(10): 1399-1401, 1996.

9. Z.Nasimuddin, N. Chen and X. Qing, "Compact circularly polarized asymmetric-slotted micro strip patch antennas", Microwave and Optical Technology Letters, 54(8):1920-1927, 2012.

\section{AUTHOR PROFILE}

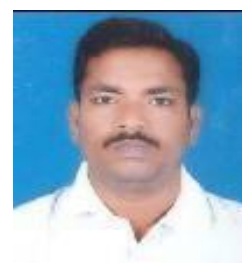

Karedla Chitambara Rao is an Associate Professor in Electronics and Communication Engineering, Aditya Institute of Technology and Management (AITAM), Tekkali, Srikakulam, Andhra Pradesh, India. He has obtained his Ph.D. Degree in Electronics and Communication Engineering from Andhra University, Visakhapatnam in 2019. M.Tech. Degree in VLSI Design from Sathyabama University in 2009 B.Tech. from JNTU, Hyderabad in 2002. Currently he is having 15 International Journals and 5 International Conferences. His research interests are Design of Multi band antennas and Optimization of Algorithms in VLSI Design. 